\title{
Biosynthesis of Immunoreactive Somatostatin by Hypothalamic Neurons in Culture
}

\author{
Hans H. Zingg and Yogesh C. Patel, Fraser Laboratories, McGill University \\ Departments of Medicine, Neurology, and Neurosurgery, Royal Victoria \\ Hospital and Montreal Neurological Institute, Montreal, Quebec H3A 1A1, \\ Canada
}

A в S TRACT The neuronal biosynthesis of somatostatin-like immunoreactivity (SLI) was investigated using mechanically dispersed neonatal rat hypothalamic cells kept in culture for up to $6 \mathrm{wk}$. Immunohistochemically, SLI was specifically localized to a small subpopulation of parvicellular neurons and their cell processes. By radioimmunoassay the cellular SLI content declined steadily during the first $2 \mathrm{wk}$ in culture (nadir value of $60 \mathrm{fmol} /$ dish at day 15) but then increased progressively to reach a maximum value of $381 \mathrm{fmol} /$ dish at day 46 . Gel chromatographic analysis showed this immunoreactivity to consist of forms corresponding to tetradecapeptide somatostatin (S-14), somatostatin-28 (S-28), and a 15,000-mol-wt molecule. After incubation of the cells with $\left[{ }^{3} \mathrm{H}\right]$ phenylalanine, the cellular extracts, purified by adsorption to $\mathrm{C}_{18}$ silica, contained material that bound specifically to an immobilized antisomatostatin antibody. Analysis by gel chromatography and high performance liquid chromatography of the specifically bound label provided evidence for the presence of labeled S-14, S-28, and the 15,000-mol-wt molecule. Pulse-chase experiments (20-min pulse, 20-min chase) demonstrated a transfer of radioactivity from the 15,000-mol-wt form to material corresponding to S-14 as well as to S-28. These studies demonstrate that cultured hy pothalamic neurons are capable of synthesizing three somatostatin-like peptides $(15,000$-mol-wt SLI, S-28, S-14), one of which $(15,000$-mol-wt SLI) serves as a biosynthetic precursor for both S-28 and S-14. This in vitro system should provide a powerful tool for further investiga-

Address all correspondence to Dr. Patel, Room M3-10. Royal Victoria Hospital, 687 Pine Avenue West, Montreal, Quebec, H3A lAl, Canada. Dr. H. H. Zingg is a Fellow of the Canadian Medical Research Council.

Received for publication 20 April 1982 and in revised form 29 July 1982. tion of the biosynthesis and regulation of biosynthesis of somatostatin in the hypothalamus.

\section{INTRODUCTION}

The cyclic tetradecapeptide somatostatin (SRIF or S$14)^{1}$ was initially identified in the hypothalamus as a growth hormone inhibitory factor (1) and subsequently in a number of other neural and nonneural tissues, including extrahypothalamic brain, pancreatic islets, gastrointestinal tract, bladder, and thyroid (24). In each of these locations the peptide has been shown to exert distinct biological effects, many of which have been proposed to be of considerable physiological importance (2-4). In view of the undoubted significance of SRIF as a regulatory peptide, as well as its characteristic distribution in both nerve and endocrine-like cells, the biosynthesis of the peptide is of considerable interest. This interest has been heightened recently by several reports demonstrating molecular heterogeneity of tissue and secreted immunoreactive somatostatin (4-12). Direct studies of the biosynthesis of SRIF have so far been carried out in detail only in the pancreas $(13,14)$. Pulse-chase studies using rat or fish islets have shown incorporation of radiolabeled amino acids into larger forms of somatostatinlike immunoreactivity (SLI) of $M_{\mathrm{r}}=8-15,000$ (fish) and $M_{\mathrm{r}}=12,500$ (rat) that are processed to SRIF (13). By contrast, very little is currently known about the biosynthesis of SRIF in the hypothalamus or other neural tissues. Studies of the neuronal biosynthesis of peptides have in general proved exceedingly difficult, and the precise mechanisms remain poorly understood, although there is evidence that the biosynthetic path-

\footnotetext{
${ }^{1}$ Abbreviations used in this paper: DME, Dulbecco's modified Eagle's medium; HPLC, high performance liquid chromatography; SLI, somatostatin-like immunoreactivity; S-28, somatostatin-28; SRIF, S-14, cyclic tetradecapeptide somatostatin: TFA, trifluoroacetic acid.
} 
ways involve high molecular weight precursors and thus resemble the scheme previously established for endocrine cells (15).

Within the central nervous system the hypothalamus contains the highest concentration of somatostatin, which is localized predominantly in parvicellular neurons present in the preoptic and anterior periventricular regions, with axons projecting to the medium eminence and the neurohypophysis $(3,4)$. We have previously characterized SLI in rat hypothalamus and identified three forms of immunoreactivity: one with a molecular weight of 15,000 , comprising $\sim 5 \%$ of total SLI (15,000-mol-wt SLI); a second form of $M_{\mathrm{r}}=3,000$ (3,000-mol-wt SLI) accounting for $\sim 25 \%$ of total SLI; and a third, dominant form of $M_{\mathrm{r}}=1,600(\sim 70 \%$ of total SLI), which corresponds to SRIF (6). Recent amino acid analyses have established the identity of 1,600-mol-wt SLI with SRIF (16) and of 3,000-mol-wt SLI with that of somatostatin-28 (S-28) (17), a biologically active 14 amino acid $\mathrm{N}$-terminally extended form of SRIF isolated from mammalian hypothalamus and intestine (18-20). Our earlier investigations on the processing of $15,000-\mathrm{mol}-\mathrm{wt}$ SLI and S-28 by hypothalamic enzymes support a possible role for both peptides as precursors for $\mathrm{S}-14(21,22)$. In the present study we have developed and characterized an in vitro system of cultured hypothalamic somatostatinergic neurons for investigating the biosynthesis of somatostatin. In particular, the experiments described here were designed both to demonstrate biosynthesis in nerve cells and to provide insight into the biosynthetic relationship between the three molecular forms of SLI.

\section{METHODS}

Synthetic S-14 was obtained from Ayerst Laboratories (Montreal, Canada). Synthetic S-28 was a generous gift of Dr. N. Ling (Salk Institute, La Jolla, CA). Molecular weight markers and Sephadex gels were purchased from Pharmacia Inc. (Montreal, Canada). Fluorescein-conjugated goat anti-rabbit IgG was obtained from Behring-Werke AG (Marburg/Lahn, West Germany). Affigel 10 was purchased from Bio-Rad Laboratories Inc. (Richmond, CA). Tritiated amino acids were obtained from New England Nuclear (Boston, MA). Tissue culture media, animal sera, and antibodies were obtained from Gibco Laboratories, Grand Island Biological Co. (Grand Island, NY). All other reagents were of analytical grade.

Hypothalamic cell cultures. Hypothalami from 2-3-dold Sprague-Dawley rats were dissected under sterile conditions using a dissecting microscope. Batches of 40 tissue fragments were triturated through a siliconized Pasteur pipette. Complete dissociation into a homogeneous cell suspension was obtained by gentle passage of the fragments through needles of decreasing inner diameter (gauge 17-21). The cells were suspended in $20 \mathrm{ml}$ of Dulbecco's modified Eagle's medium (DME) and plated in 35-mm-Diam plastic Petri dishes (Falcon Labware, Div. Becton-Dickinson, Oxnard, CA) at a concentration of $2-5 \times 10^{6}$ cells/dish (equivalent to one hypothalamus/dish), and kept in a humidified atmosphere of $5 \% \mathrm{CO}_{2}: 95 \%$ air at $37^{\circ} \mathrm{C}$. The culture medium consisted of $80 \%$ DME supplemented with $6 \mathrm{~g} /$ liter glucose, $80 \mathrm{mU} / \mathrm{ml}$ insulin (Toronto insulin, Connaught Laboratories, Willowdale, Ontario), penicillin, streptomycin, and fungizone $(100 \mathrm{U} / \mathrm{ml}, 0.25 \mu \mathrm{g} / \mathrm{ml}$, and $100 \mu \mathrm{g} / \mathrm{ml}$, respectively), as well as $10 \%$ fetal bovine serum and $10 \%$ horse serum (during the first $7 \mathrm{~d}$ ), or $10 \%$ horse serum alone (from day 7 onwards). The medium was changed every $7 \mathrm{~d}$. The morphological development of the cultures was monitored by phase contrast microscopy. Any pretreatment of the dishes to facilitate cell attachment proved to be unnecessary because the cells attached directly to the bottom of the plastic petri dishes, provided that the cultures were left undisturbed during the first $7 \mathrm{~d}$ after plating. Under the conditions used, a balanced development of nondividing neuronal cells and the dividing supporting cells was achieved for periods of at least $6 \mathrm{wk}$, never necessitating the use of an antimetabolite to kill dividing cells. Preliminary experiments indicated that treatment with cytosin-arabinoside for the first $5 \mathrm{~d}$ resulted in cultures with exceedingly low SLI content.

Release of SLI from cultured cells. Groups of 10 dishes were incubated for three consecutive $1-\mathrm{h}$ periods with bicarbonate-buffered salt solution. The $\mathrm{K}^{+}$concentration was $4.6 \mathrm{mM}$ for the first two periods and elevated to $50 \mathrm{mM}$ for the third period (with a concomitant lowering of $\mathrm{Na}^{+}$concentration to maintain isoosmolality). In a separate experiment, the same protocol was adopted except that $\mathrm{Ca}^{++}(2.2$ $\mathrm{mM}$ ) was omitted and $2 \mathrm{mM} \mathrm{Na}$ EDTA added instead. Media from the second and third incubation periods as well as cell extracts at the end of the experiments were assayed for SLI. To obtain chromatographic characterization of released SLI, similar experiments were performed using a group of 30 dishes. Media from the second and third incubation period (with $\mathrm{Ca}^{++}$included) were pooled separately and kept for further analysis.

Measurement and characterization of SLI. To determine the SLI content of the cultures, the cells were scraped in $1 \mathrm{ml} 1 \mathrm{M}$ acetic acid and extracted by sonication on ice followed by boiling $(5 \mathrm{~min})$ and centrifugation at $1,000 \mathrm{~g}$ for $10 \mathrm{~min}$. The supernatant containing the solubilized SLI was evaporated to dryness using a rotary evaporator (SpeedVac, Savant Instruments, Inc., Hicksville, NY), dissolved in $0.05 \mathrm{M} \mathrm{PO}_{4}$ buffer, pH 7.5, and measured for SLI by radioimmunoassay (RIA) using a rabbit antibody with specificity directed toward the central region of the $S-14$ sequence (7). To achieve further characterization by gel chromatography, samples containing SLI were fractionated on Sephadex G-50 columns eluted with $6 \mathrm{M}$ urea, $0.05 \mathrm{M} \mathrm{PO}_{4}, \mathrm{pH}$ 7.5. SLI in each fraction was determined by RIA. The column was calibrated with the following markers (all equally boiled in $6 \mathrm{M}$ urea for $5 \mathrm{~min}$ ): $\mathrm{S}-14$ and $\mathrm{S}-28$, ribonuclease $A$, chymotrypsinogen $A$, and dextran blue. Samples were prepared as follows: (a) neonatal hypothalamic tissue freshly obtained from five animals was extracted in $1 \mathrm{ml} 1 \mathrm{M}$ acetic acid by sonication and boiling (4). A $0.1-\mathrm{ml}$ aliquot of the extract was mixed with $0.9 \mathrm{ml}$ of column buffer for analysis. (b) Cultured cells from 10 dishes were pooled and extracted in $1 \mathrm{M}$ acetic acid as described above. After evaporation of the acetic acid, the extracts were dissolved in $1 \mathrm{ml}$ of column buffer. (c) Media from 30 dishes (from the release experiments) were pooled and the SLI concentrated by passage through a small octadecasilylsilica cartridge (Sep-Pak, Waters Associates, Milford, MA). The retained material (containing SLI) was eluted with $2 \mathrm{ml}$ acetonitrile:water:trifluoroacetic acid (TFA) (80:19:1, by volume) (23). After removal of the solvent by evaporation, the residue was reconstituted in $1 \mathrm{ml}$ column buffer. 
Immunohistochemistry and silver staining. Cells cultured for $20 \mathrm{~d}$ were fixed in $2 \%$ paraformaldehyde, $0.2 \%$ picric acid in phosphate-buffered saline (PBS) for $24 \mathrm{~h}$, followed by a short exposure to $90 \%$ alcohol to increase cell membrane permeability. A rabbit antibody prepared against S-14 was then applied at a $1: 30$ dilution for $2 \mathrm{~h}$ at $20^{\circ} \mathrm{C}$. After rinsing with PBS, fluorescein-conjugated goat anti-rabbit IgG was applied at a 1:25 dilution for $1 \mathrm{~h}$ at $20^{\circ} \mathrm{C}$. The cultured cells were then washed with PBS, counterstained with Evans blue $(0.01 \%$ in PBS), and mounted in glycerol PBS (1:1). Specificity of staining was tested by using somatostatin antibody that was preabsorbed with $10^{-5} \mathrm{M}$ synthetic $\mathrm{S}-14$ before use. The dishes were then viewed under a Reichert fluorescence and phase-contrast microscope (Reichert Biovert, Vienna). For specific staining of neurons and neurofibers, cells were fixed as described above and the Bodian method for silver impregnation was applied (23).

Incubation of cultures with $\left[{ }^{3} H\right]$ phenylalanine. Since the sequence of S-14 contains three phenylalanine residues, $\left[{ }^{3} \mathrm{H}\right]$ phenylalanine was chosen as the labeled precursor for studying the incorporation of amino acids into SLI. Groups of 40 dishes containing 20-30-d-old cultures were incubated with Dulbecco's phosphate-buffered salt solution for $30 \mathrm{~min}$ followed by incubation with $0.5 \mathrm{ml}$ of the same medium containing in addition $12.5 \mu \mathrm{Ci} / \mathrm{ml}$ of $\left[{ }^{3} \mathrm{H}\right]$ phenylalanine for variable amounts of time. For pulse-chase studies, the pulse incubation period was followed by a chase period in which cycloheximide $(250 \mu \mathrm{g} / \mathrm{ml})$ was added and the label was replaced by unlabeled phenylalanine in a $>100$-fold excess. The cells were then scraped from the dishes, extracted with $1 \mathrm{M}$ acetic acid as described above, and the labeled SLI purified and characterized. To estimate the amount of radioactivity incorporated into protein in relation to the time of exposure to tracer, groups of 10 dishes were incubated with label for $0,30,60$, and $120 \mathrm{~min}$ at $37^{\circ} \mathrm{C}$ and proteins in the tissue extracts as well as in the incubation media were precipitated with $10 \%$ trichloracetic acid (TCA). After centrifugation, the pellets were washed twice in TCA, dissolved in $0.5 \mathrm{ml} 0.5 \mathrm{M} \mathrm{NaOH}$, and counted in a Packard liquid scintillation spectrometer (Packard Instrument Company, Inc., Downers Grove, IL).

Purification of labeled SLI. The initial step was aimed at removing unincorporated label from the extracts by passage through a Sep-Pak cartridge as described above (24). The cartridge was washed with $20 \mathrm{ml} 1 \mathrm{M} \mathrm{NaCl}$ and the adsorbed peptides eluted with acetonitrile:water:TFA (80:19:1 $\mathrm{vol} / \mathrm{vol}$ ). Recovery of endogenous hypothalamic SLI (comprising 15,000-mol-wt SLI, S-28, and S-14) from Sep-Pak cartridges was comparable for the three molecular species and averaged $88 \pm 6 \%$.

The second step involved further purification by immunoaffinity chromatography. For this, the SLI containing eluate from the Sep-Pak cartridge was evaporated to dryness and the residue reconstituted in $40 \mathrm{ml} 50 \mathrm{M} \mathrm{PO}_{4}$ buffer, $\mathrm{pH}$ 7.5 , containing $0.5 \mathrm{M} \mathrm{NaCl}, 0.1 \%$ bovine serum albumin (BSA), and $0.01 \%$ Triton $X$. This solution was then applied to an antisomatostatin affinity column prepared by coupling IgG precipitated by polyethylene glycol from $2.4 \mathrm{ml}$ of sheep antisomatostatin serum to $25 \mathrm{G}$ Affigel 10 (total column capacity $1 \mu \mathrm{g} \mathrm{S-14)}(7)$. The column was then rinsed with an additional $200 \mathrm{ml}$ of starting buffer to remove nonspecifically adsorbed protein, and specifically bound material was eluted with $2 \mathrm{M}$ acetic acid or an excess of ligand (40 $\mu \mathrm{g} \mathrm{S}$ 14). Label eluting in the presence of excess ligand was found to be quantitatively and qualitatively identical to that eluting with $2 \mathrm{M}$ acetic acid. After concentration by rotary evaporation, the SLI eluted from the affinity column was frac- tionated on a Sephadex G-50 column equilibrated with $2 \mathrm{M}$ acetic acid. Radioactivity in each sample was determined by liquid scintillation spectrometry. Recovery of total endogenous hypothalamic SLI (consisting of 15,000-mol-wt SLI, S-28, and S-14) from the immunoaffinity column was $82 \pm 10 \%$ with no significant difference in the relative recoveries of the three molecular forms of SLI.

High performance liquid chromatography (HPLC). Peak fractions of radioactivity from the Sephadex chromatography step corresponding to S-14 and S-28 were further analyzed by HPLC. For this procedure the fractions were rotary evaporated, resuspended in a total volume of $0.4 \mathrm{ml} 30 \%$ aqueous acetonitrile, and analyzed. A $\mu$ Bondapak C-18 column (Waters Associates, Inc.) was eluted with a gradient from 30 to $50 \%$ aqueous acetonitrile. In addition, the solvent system contained $0.1 \mathrm{M} \mathrm{Na}$ acetate and $0.2 \%$ heptafluorobutryic acid (22). Aliquots of the fractions were analyzed for SLI by RIA and radioactivity was measured by liquid scintillation spectrometry.

\section{RESULTS}

Characterization of hypothalamic cultures. Immediately after being plated, all cells exhibited a uniform round-shaped appearance and were evenly distributed on the plate surface. After day 5 in culture, many cells showed a tendency to aggregate, and in addition developed processes that made contact with neighboring cells or cell processes. After $20 \mathrm{~d}$ in culture, a confluent layer of fibroblast-like cells covered most of the surface of the dish, with the neural cells on top forming an increasingly complex network of processes connecting either individual neurons or neuron clusters. In addition, cells with the morphology of astrocytes and oligodendrocytes were observed to contact several neighboring neurons by means of short processes (Fig. 1[a, b]). Determination of SLI content by RIA showed that the initial cell suspension before plating contained an average of $1.7 \mathrm{pmol} \mathrm{SLI} / \mathrm{ml}$ However, as shown in Fig. 2, the SLI content of the cultured cells diminished dramatically to $120 \mathrm{fmol} /$ dish at day 2 and thereafter declined more gradually over the next $2 \mathrm{wk}$ to reach a nadir of $\sim 60 \mathrm{fmol} / \mathrm{dish}$ at day 15 . During the subsequent $4 \mathrm{wk}$ there was a progressive increase in the cellular content of SLI reaching a mean value of $381 \mathrm{fmol} /$ dish at day 46 , which was sixfold greater than the nadir value observed at day 15 . This suggests that most of the SLI present in the cultures after day 15 is the result of de novo in vitro synthesis. To localize SLI-containing cells, immunohistochemical methods were applied. As illustrated in Fig. 1 (c, d), specific immunofluorescence was observed in the perikaryon and processes of scattered cells that corresponded morphologically to small neurons. Within the cell processes immunopositive material was observed as granular fluorescence localized in endings as well as in axonal varicosites.

Gel chromatographic characterization of the SLI 

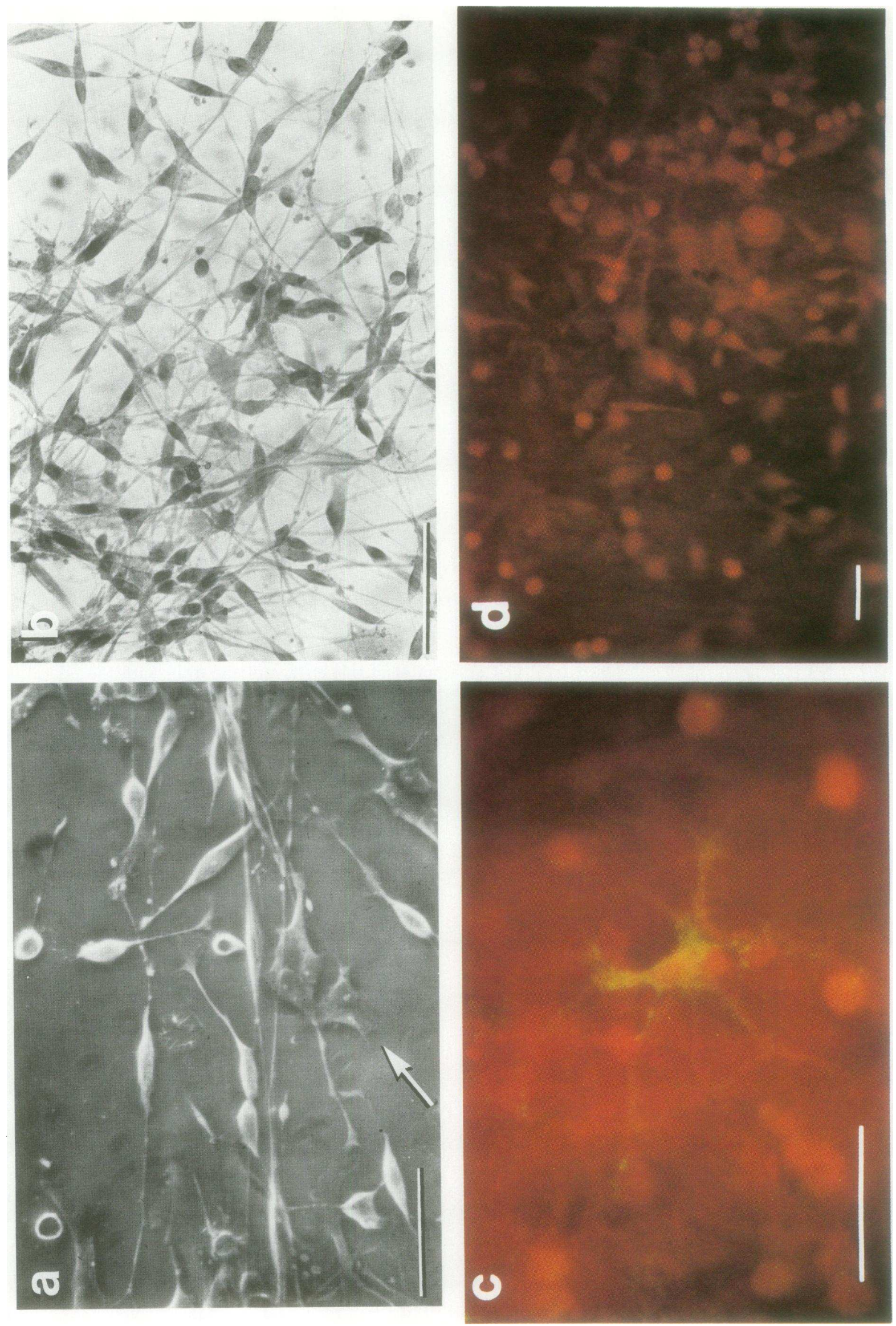
Figure 1 a. Phase-contrast microscopy of dispersed rat neonatal hypothalamic cells in culture at day 21 . Note neuronal cell bodies with axonal and dendritic processes as well as supporting nonneuronal cells (arrow). b. Bodian stain of hypothalamic culture (day 21). c and d. Immunofluorescent localization of somatostatin-containing neurons in hypothalamic cultures (day 25 ). In $\mathrm{d}$, the antisomatostatin antibody was previously absorbed with $10^{-5} \mathrm{M} \mathrm{S-14}$. Note positively stained small neuron and cell processes in $c$ and the absence of positive staining in $d$.

Scale bars, $50 \mu \mathrm{m}$.

produced by the cultures revealed three molecular forms of SLI of which the largest one $\left(K_{\mathrm{D}}=0.11\right)$ corresponded to a $M_{\mathrm{r}}$ of 15,000 and the remaining two coeluted with synthetic S-28 $\left(K_{\mathrm{D}}=0.48\right)$ and S-14 $\left(K_{\mathrm{D}}\right.$ $=0.73)$, respectively (Fig. $3 \mathrm{~A})$. The relative amounts of the three forms $(23,14,63 \%$ of total immunoreactivity) were similar to those observed on gel chromatographic analysis of neonatal hypothalamic tissues (15,000-mol-wt SIII, 19\%; S-28, 9\%; S-14, 72\%). The profile, however, differed markedly from that previously reported for adult rat hypothalamic tissue $(5,6)$ in showing a relatively greater abundance of 15,000 mol-wt SLI and lesser quantities of S-28 equivalent immunoreactivity. SLI released into the medium increased from a basal value of $8.7 \pm 2.4 \%$ of total content $/ \mathrm{h}$ to $18.1 \pm 3.3 \%$ of total content/h in response to $\mathrm{K}^{+}$stimulation. This increase in release was specific and did not occur in the absence of $\mathrm{Ca}^{++}$(basal, $9.8 \pm 2.7 \% ; \mathrm{K}^{+}$stimulation, $9.2 \pm 2.3 \%$ ). Chromatographic analysis of SLI released into the medium after $50 \mathrm{mM} \mathrm{K}^{+}$stimulation (Fig. 3B) revealed three peaks of immunoreactivity corresponding to 15,000 -mol-wt SLI, S-28, and S-14 (28, 6, and $66 \%$ of total SLI, respectively).

Incorporation of $\left[{ }^{3} \mathrm{H}\right]$ phenylalanine into SLI. Over a 2-h period, a progressive incorporation of label into TCA-precipitable material was observed (Table I). The

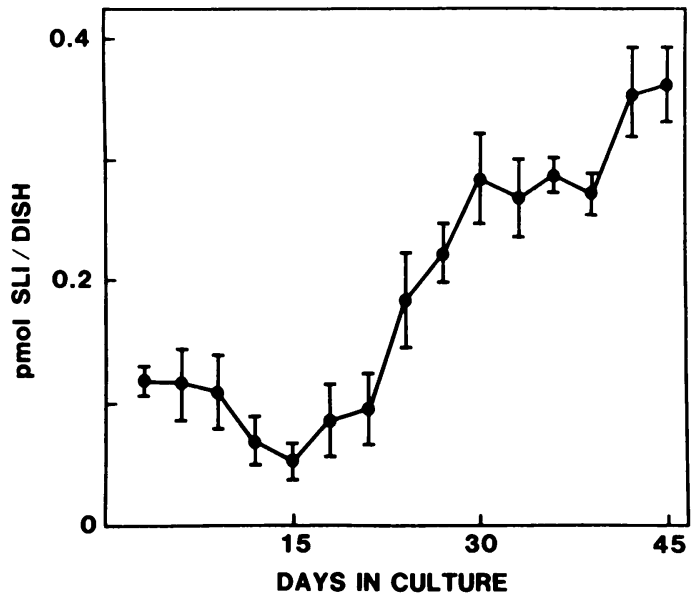

FIGURE 2 SLI content of extracts of cultured hypothalamic cells measured by RIA at different times after plating. Each value represents mean \pm SEM of four dishes. rate of incorporation corresponded to $1.03 \times 10^{6} \mathrm{dpm} /$ $\mathrm{mg}$ protein during the first hour. The rate of incorporation of label into materials retained on Sep-Pak

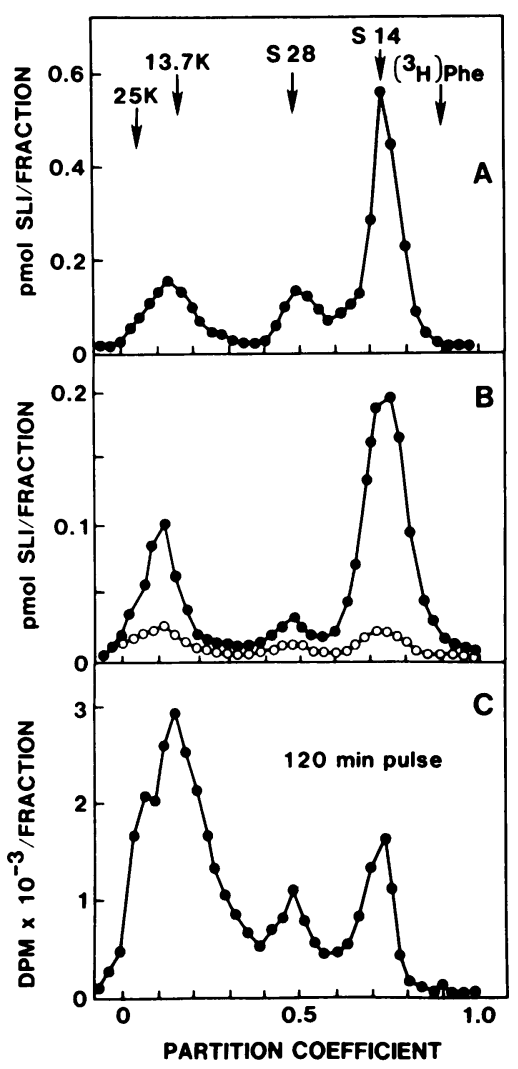

FIGURE 3 A. Characterization of SLI in extracts of cultured hypothalamic cells by gel filtration. A Sephadex G-50 column (superfine $1 \times 56 \mathrm{~cm}$ ) was eluted with $6 \mathrm{M}$ urea $0.05 \mathrm{M} \mathrm{PO}_{4}$. SLI in each fraction was measured by RIA. The elution volume is expressed as partition coefficient $K_{\mathrm{D}}$, where 0 is the void volume and 1 is the salt volume. Markers: ribonuclease A $(25 \mathrm{~K})(25,000 \mathrm{~mol} \mathrm{wt})$; chymotrypsinogen A (13.7K) $(13,700$ mol wt); synthetic S-28 (S 28); synthetic S-14 (S 14); ${ }^{3} \mathrm{H}$-labeled phenylalanine $\left(\left[{ }^{3} \mathrm{H}\right] \mathrm{Phe}\right)$. B. Elution profiles of SLI present in pooled media after a $1-h$ incubation period in normal buffer $(O)$ and in buffer containing $50 \mathrm{mM} \mathrm{K}^{+}$ (๑). Buffer composition was (in millimolars): $\mathrm{Na}^{+}, 146$ (or 101 ); $\mathrm{K}^{+}, 4.7$ (or 50); $\mathrm{Ca}^{++}, 1.1 ; \mathrm{Mg}^{++}, 1.0 ; \mathrm{HCO}_{3}{ }^{-}, 25 ; \mathrm{Cl}^{-}$, 130; glucose, 10; $\mathrm{BSA}, 0.1 \%$; $\mathrm{pH} 7.4$ at air: $\mathrm{CO}_{2}(95: 5)$. $-\mathrm{O}-, 4.6 \mathrm{mM} \mathrm{K}^{+} ;-\bigcirc-, 50 \mathrm{mM} \mathrm{K}^{+}$. C. Elution profile of ${ }^{3} \mathrm{H}$-labeled SLI purified from extracts of 40 dishes incubated for $2 \mathrm{~h}$ in the presence of $\left[{ }^{3} \mathrm{H}\right]$ phenylalanine. 
TABLE I

Incorporation of $\left[{ }^{3} \mathrm{H}\right]$ Phenylalanine into TCA-Precipitable Material and into Material Adsorbing to C-18 Silica (Sep-Pak) by Cultured Hypothalamic Cells (Day 20)

\begin{tabular}{lcccr}
\hline & \multicolumn{4}{c}{ Incubation time $(\min )$} \\
\cline { 2 - 5 } & 0 & 30 & 60 & 120 \\
\hline & \multicolumn{4}{c}{$d p m 0^{-3} /$ dish } \\
TCA precipitation & & & & \\
$\quad$ Cells & 0.864 & 41.81 & 71.20 & 102.61 \\
$\quad$ Medium & 0.923 & 1.07 & 1.74 & 3.64 \\
Sep-Pak adsorption & & & & \\
$\quad$ Cells & 0.971 & 14.54 & 24.48 & 31.36 \\
\hline
\end{tabular}

Pools of 10 culture dishes were incubated at $37^{\circ} \mathrm{C}$ in $0.5 \mathrm{ml} \mathrm{DME}$ containing $\left[{ }^{3} \mathrm{H}\right]$ phenylalanine $\left(30 \times 10^{6} \mathrm{dpm} / \mathrm{ml}\right)$ for the times indicated and proteins in cell extracts and media were precipitated with TCA. In addition, all extracts were passed through a Sep-Pak cartridge and the adsorbed material was eluted with $2 \mathrm{ml}$ acetonitrile:water:TFA (80:19:1, by volume). Control values ( $0 \mathrm{~min})$ were obtained by removing cells and media immediately after addition of tracer

C-18 cartridge amounted to only around one-third of the TCA-precipitable counts, at all time points examined. An average of $11.5 \%$ of the label present in the extract after a 2 -h labeling period was retained on the Sep-Pak cartridge. During the subsequent affinity chromatography step, a mean of $0.33 \%$ of the applied labeled material was specifically bound. The elution profile on Sephadex G-50 of the purified ${ }^{3} \mathrm{H}$-labeled SLI is shown in Fig. 3C. Approximately 50, 15, and $25 \%$ of labeled material eluted in positions corresponding to 15,000-mol-wt SLI, S-28, and S-14, respectively. Approximately $10 \%$ eluted in a position before that of 15,000 exhibiting an apparent $M_{\mathrm{r}}$ of $>15,000$. Peak fractions of the $\left[{ }^{3} \mathrm{H}\right]$ phenylalanine-labeled material coeluting with S-28 and S-14 were further analyzed by HPLC. The results (Fig. 4) showed that $65 \%$ of the counts coeluting with S-14 on Sephadex G-50 and $60 \%$ of the counts coeluting with S-28 possessed identical retention times to their synthetic counterparts.

Pulse-chase experiments. To test for possible precursor-product relationships between labeled 15,000mol-wt SLI, S-28, and S-14, pulse incubations of 5-20 min duration were performed and followed by a 20 min chase period. As depicted in Fig. 5, conversion of label eluting at $K_{\mathrm{D}}=0.05-0.20$ into material eluting in the positions of S-28 and S-14 was observed. Whereas after the 20 -min pulse period $85 \%$ of the total radioactivity eluted at $K_{\mathrm{D}}=0.05-0.20$, after $20 \mathrm{~min}$ of chase, this amount had decreased to $35 \%$ with a concomitant increase in the proportion of label eluting at $K_{\mathrm{D}}=0.65-0.75(\mathrm{~S}-14)$. Furthermore, after the chase period, an additional peak of label appeared at $K_{\mathrm{D}}$ $=0.45$, which was not present after the $20-\mathrm{min}$ pulse period and which corresponded in its elution position to $\mathrm{S}-28$.

\section{DISCUSSION}

The investigation of somatostatin biosynthesis in nerve cells has proved difficult because of inavailability of a suitable neural tissue containing a relatively pure population of somatostatin cells. Because the hypothalamus contains the highest concentration of immunoreactive somatostatin in the brain (4), we have developed in the present study an in vitro system of cultured neonatal hypothalamic neurons and characterized it with respect to its ability to synthesize and release SLI. For elucidation of the biosynthetic relationships between 15,000-mol-wt SLI, S-28, and S-14, the hypothalamus offers the distinct advantage of containing substantial quantities of all three molecular forms as opposed to tissues such as the pancreas, which have been studied previously (5). Primary cultures of dispersed hypothalamic and cerebrocortical cells derived from fetal rat brain and containing SLI have recently been described from two laboratories $(25,26)$. The cellular content as well as the release of SLI from

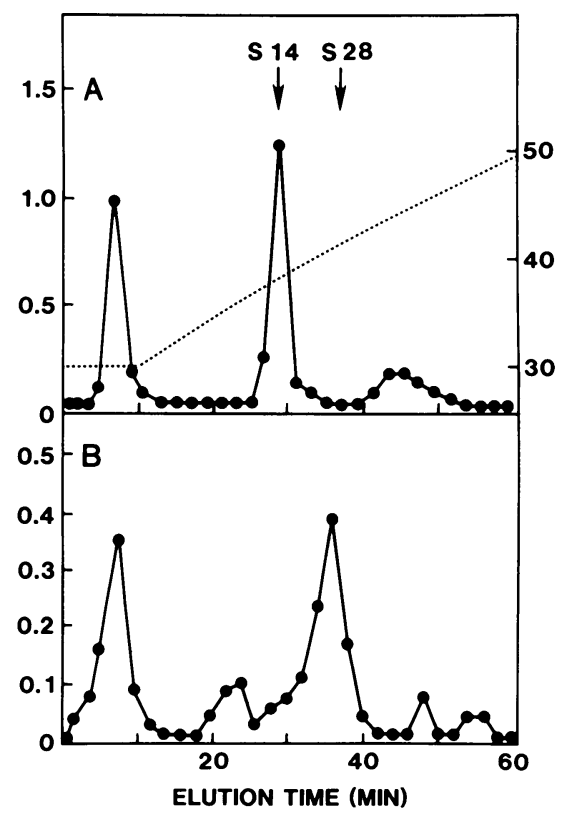

Figure 4 HPLC of the peaks of labeled material coeluting on Sephadex G-50 either with synthetic S-28 (A) or with S14 (B). Labeled compounds eluting on Sephadex G-50 at $K_{D}$ $=0.40-0.50(\mathrm{~A})$ or at $K_{\mathrm{D}}=0.65-0.75(\mathrm{~B})$ were evaporated to dryness and analyzed by HPLC. Arrows indicate the elution position of synthetic S-28 and S-14. Dashed line, \% acetonitrile; $-0, \mathrm{dpm} \times 10^{-3} /$ fraction. 


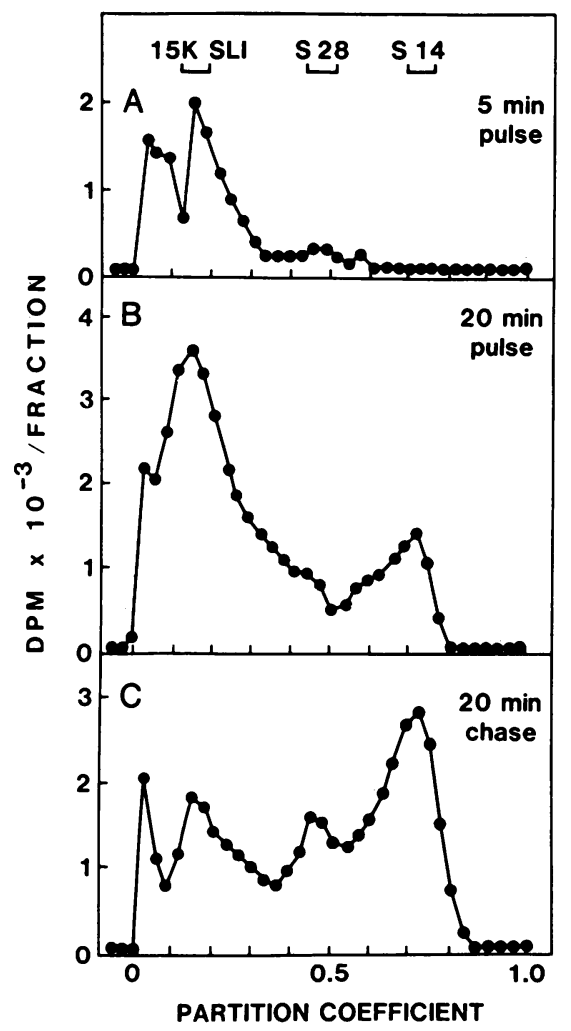

Figure 5 Elution profile on Sephadex G-50 of labeled SLI purified from cell extracts following pulse-chase studies. 20 dishes were incubated for either $5 \mathrm{~min}$ (A) or $20 \mathrm{~min}$ (B and C) in the presence of $\left[{ }^{3} \mathrm{H}\right]$ phenylalanine. In $\mathrm{C}$, the pulse period was followed by a $20-\mathrm{min}$ chase period. $15 \mathrm{~K}=15,000$ mol wt.

the cultured neonatal hypothalamic cells in the present study are comparable to those reported for the two fetal tissues. However, specific somatostatin-positive neurons were identified by immunocytochemistry only in cultured cerebrocortical cells (26). In the present study, we have examined the immunofluorescent localization of somatostatin and demonstrated specific staining in a subpopulation of cultured hypothalamic neurons. These neurons comprised a small proportion $(\sim 1 \%)$ of the total population of nerve cells, a finding compatible with the density of somatostatin-positive neurons observed in sections of rat hypothalamus (27). Nonetheless, this system was found to be a convenient source of somatostatin-synthesizing neurons.

Two separate lines of evidence attest to the biosynthesis of SLI in the neuronal cultures. Firstly, time course studies of the total content of SLI present in the cultures at different times after plating suggest that the SLI present in the cultures after the second week originates from de novo synthesis during the culture period. The progressive increase in the cellular SLI content from the second to the sixth week indicates maintenance of viability of the somatostatinergic neurons and continuing synthesis of SLI during this period. Characterization of the newly synthesized SLI by gel chromatography and RIA showed three peaks of immunoreactivity corresponding to 15,000 -mol-wt SLI, $\mathrm{S}-28$, and S-14, in amounts similar to those found in extracts of newborn rat hypothalami. This suggests that all three known tissue forms of SLI have been synthesized by the cultured somatostatin cells. However, the relative amounts of 15,000-mol-wt SLI and $\mathrm{S}-28$ in fresh neonatal hypothalamic tissue or cultured neonatal hypothalamic cells were different from those previously reported for adult hypothalamus $(5,6)$. Secondly, the pulse-labeling studies showed incorporation of $\left[{ }^{3} \mathrm{H}\right]$ phenylalanine into labeled peptides that corresponded to S-14, S-28, and 15,000-mol-wt SLI. This was demonstrated by detailed analyses of the labeled peptides using both immunological and chromatographic techniques and involved initial separation of the unincorporated radioactivity by $\mathrm{C}-18$ silica cartridges followed by isolation of the SLI by immunoaffinity chromatography and characterization of the individual immunoreactive components by gel filtration and HPLC. In addition to the three known forms of SLI, labeled material of an apparent $M_{\mathrm{r}}>15,000$ was also retained on the affinity column. The nature of this very high $M_{\mathrm{r}}$ SLI remains uncertain. As gel chromatography was performed under denaturing conditions, it is unlikely that this material represents protein-bound or aggregated SLI.

Results from the pulse-chase experiments suggest that after a short pulse period, label is preferentially incorporated into a form corresponding in its elution position on gel chromatography to 15,000 -mol-wt SLI, whereas during the following chase period, transfer of label is observed from the 15,000 -mol-wt region to peaks eluting in the position of S-14 and S-28. No transfer of label from the very high $M_{\mathrm{r}}$ peak (>15,000-molwt SLI) to compounds of smaller molecular size was observed during these pulse-chase experiments. These findings suggest a precursor-product relationship between 15,000-mol-wt SLI and S-28 and S-14 and are consistent with our earlier studies of the processing of 15,000 -mol-wt SLI by rat hypothalamic enzymes in which sequential breakdown of 15,000 -mol-wt SLI to S-28 and S-14 was demonstrated (21). After the chase period relatively little material eluted in the position of S-28 compared with the marked accumulation of material coeluting with $S-14$. This could be due to a direct conversion of $15,000-\mathrm{mol}-\mathrm{wt}$ SLI into S-14 or to a very rapid conversion of newly formed S-28 to S14. Separate evidence for the existence of the latter pathway has been obtained in recent studies demonstrating conversion of S-28 to S-14 by hypothalamic 
synaptosomes (22). Although the present data do not permit a final conclusion regarding the relative importance of the two potential biosynthetic pathways leading to S-14 (i.e., directly from 15,000-mol-wt SLI or via $\mathrm{S}-28$ as an intermediate), they do provide evidence that 15,000 -mol-wt SLI is a precursor for both S-28 and S-14.

Somatostatin biosynthesis has previously been investigated in detail in the pancreas and almost exclusively in the fish pancreas $(13,14,28-30)$. These studies have culminated in the identification and sequencing of two separate cDNAs derived from anglerfish islet mRNAs that encode for two distinct somatostatin peptides (preprosomatostatins 1 and 2) of $M_{\mathrm{r}} 13,300$ and 14,100 (30). One of these molecules contains the exact sequence of $\mathrm{S}-14$ at the $\mathrm{C}$-terminus but neither peptide exhibits the complete $\mathrm{S}-28$ sequence. In contrast to the fish, relatively few studies of somatostatin biosynthesis have been conducted in mammalian tissues and especially in nonpancreatic tissues. Joseph-Bravo et al. have reported the isolation from rodent hypothalami of mRNA that codes for a 15,000 -mol-wt polypeptide immunologically related to somatostatin (31). Recently, cDNA prepared from mRNA isolated from a rat medullary thyroid carcinoma has been shown to code for a precursor of approximately 130 amino acid residues, which contains the entire sequence of S-28 at the C-terminus and which could thus represent a possible precursor for S-28 and S-14 (32). Using isolated rat islets, Patzelt et al. identified a 12,500-molwt prosomatostatin molecule following a short (1-2 min) pulse incubation with radioactive amino acids, which was processed to S-14 during a 30-120-min chase period (14). The large precursor molecule demonstrated in mammalian tissues in each of these three studies corresponds in size to the 15,000-mol-wt SLI form identified in the rat hypothalamus in the present study. Furthermore, the kinetics of somatostatin biosynthesis in rat islets (14) appear comparable to those observed in the rat hypothalamus. However, major differences exist between the two systems, especially with respect to S-28, which was not identified in the islet studies.

In conclusion, we have demonstrated that cultured normal rat hypothalamic neurons represent a suitable system for investigating neuronal biosynthesis of somatostatin-like peptides and particularly for future studies aimed at elucidating the relative physiological significance of the one or more pathways leading to S-14 formation as well as the regulation of biosynthesis.

\section{ACKNOWLEDGMENTS}

We thank Miss. I. Pierzchala for technical assistance and Mrs. M. Correia for secretarial help.
This study was supported by grants from the Canadian Medical Research Council (MA 6196) and the U. S. Public Health Service (AM 21373).

\section{REFERENCES}

1. Brazeau, P., W. Vale, R. Burgus, W. Ling, M. Butcher, J. Rivier, and R. Guillemin. 1973. Hypothalamic polypeptide that inhibits the secretion of immunoreactive growth hormone. Science (Wash. DC). 179: 77-79.

2. Patel, Y. C., H. H. Zingg, D. Fitz-Patrick, and C. B. Srikant. 1981. Somatostatin: some aspects of its physiology and pathophysiology. In Gut Hormones. S. R. Bloom and J. M. Polak, editors. Churchill-Livingstone, Edinburgh. 2nd edition. 39-49.

3. Reichlin, S. 1981. Systems for the study of regulation of neuropeptide secretion. In Neurosecretion and Brain Peptides. J. B. Martin, S. Reichlin, and K. L. Bick, editors. Raven Press, New York. 573-597.

4. Patel, Y. C., and S. Reichlin. 1978. Somatostatin in hypothalamus, extrahypothalamic brain and peripheral tissues of the rat. Endocrinology. 102: 523-530.

5. Patel, Y. C., T. Wheatley, and C. Ning. 1981. Multiple forms of immunoreactive somatostatin: comparison of distribution in neural and non-neural tissues and portal plasma of the rat. Endocrinology. 109: 1943-1949.

6. Zingg, H. H., and Y. C. Patel. 1979. Somatostatin precursors: evidence for presence in and release from rat median eminence and neurohypophysis. Biochem. Biophys. Res. Commun. 90: 466-472.

7. Patel, Y. C., T. Wheatley, D. Fitz-Patrick, and G. Brock. 1980. A sensitive radioimmunoassay for immunoreactive somatostatin in extracted plasma; measurement and characterization of portal and peripheral plasma in the rat. Endocrinology. 107: 306-313.

8. Spiess, J., and W. Vale. 1980. Multiple forms of somatostatin-like activity in rat hypothalamus. Biochemistry. 19: 2861-2866.

9. Trent, F., and G. C. Weir. 1981. Heterogeneity of somatostatin-like peptides in rat brain, pancreas and gastrointestinal tract. Endocrinology. 108: 2033-2038.

10. Lauber, M., M. Camier, and P. Cohen. 1979. Higher molecular weight forms of immunoreactive somatostatin in mouse hypothalamic extracts: evidence of processing in vitro. Proc. Natl. Acad. Sci. USA. 76: 6004-6008.

11. Rorstadt, O. P., J. Epelbaum, P. Brazeau, and J. B. Martin. 1979. Chromatographic and biological properties of immunoreactive somatostatin in hypothalamic and extra hypothalamic brain regions of the rat. Endocrinology. 105: 1083-1092.

12. Zyznar, E. S., J. M. Conlon, V. Schusdziarra, and R. H. Unger. 1979. Properties of somatostatin-like immunoreactive polypeptides in the canine extrahypothalamic brain and stomach. Endocrinology. 105: 1426-1431.

13. Noe, B. D., D. J. Fletcher, G. E. Bauer, G. C. Weir, and Y. C. Patel. 1978. Somatostatin biosynthesis occurs in pancreatic islets. Endocrinology. 102: 1675-1685.

14. Patzelt, C., H. S. Tager, R. J. Carroll, and D. F. Steiner. 1980. Identification of prosomatostatin in pancreatic islets. Proc. Natl. Acad. Sci. USA. 77: 2410-2414.

15. Brownstein, M. J., J. F. Russell, and H. Gainer. 1980. Synthesis, transport, and release of posterior pituitary hormones. Science (Wash., DC). 207: 373-378.

16. Bohlen, P., R. Benoit, N. Ling, R. Guillemin, and P. Brazeau. 1981. Isolation and characterization of rat hypothalamic somatostatin-14. Endocrinology. 108: 20082010. 
17. Bohlen, P., R. Benoit, F. Esch, N. Ling, P. Brazeau, and R. Guillemin. 1981. Isolation and characterization of somatostatin-related peptides from rat tissue. Proceedings of the 2nd International Symposium on Somatostatin. June, 1981, Athens, Greece. p. 13. (Abstr.).

18. Pradayrol, L., H. Jornvall, V. Mutt, and A. Ribet. 1980. N-terminally extended somatostatin: the primary structure of somatostatin-28. FEBS (Fed. Eur. Biochem. Soc.) Lett. 109: 55-58.

19. Schally, A. V., W. Huang, R. C. C. Chang, A. Arimura, T. W. Redding, R. P. Millar, M. W. Hunkapiller, and L. E. Hood. 1980. Isolation and structure of pro-somatostatin: a putative somatostatin precursor from pig hypothalamus. Proc. Natl. Acad. Sci. USA. 77: 4489-4493.

20. Esch, F., P. Bohlen, N. Ling, R. Benoit, P. Brazeau, and R. Guillemin. 1980. Primary structure of ovine hypothalamic somatostatin-28 and somatostatin-25. Proc. Natl. Acad. Sci. USA. 77: 6827-6831.

21. Zingg, H. H., and Y. C. Patel. 1980. Processing of somatostatin precursors: evidence for enzymatic cleavage by hypothalamic extract. Biochem. Biophys. Res. Commun. 93: 1274-1279.

22. Zingg, H. H., and Y. C. Patel. 1982. Processing of synthetic somatostatin-28 and a related endogeneous rat hypothalamic somatostatin-like molecule by hypothalamic enzymes. Life Sci. 30: 525-533.

23. Luna, L. 1968. Manual of histologic staining methods of the Armed Forces Institute of Pathology. McGraw Hill Book Company, New York. 197-198, 215-216.

24. Bennet, H. P., A. M. Hudson, C. Martin, and G. E. Purdon. 1977. Use of octadecasilyl-silica for the extraction and purification of peptides in biological samples. Biochem. J. 168: 9-13.

25. Gamse, R., E. Vaccaro, G. Gamse, M. Di Pace, T. Fox, and S. E. Leeman. 1980. Release of immunoreactive somatostatin from hypothalamic cells in culture: inhibition by gamma-aminobutyric acid. Proc. Natl. Acad. Sci. USA. 77: 5551-5556.

26. Delfs, J., R. Robbins, J. L. Connolly, M. Dichter, and S. Reichlin. 1980. Somatostatin production by rat cerebral neuroses in dissociated cell culture. Nature (Lond.). 283: 676-677.

27. Hockfelt, T., O. Johansson, M. Schultzberg, S. Efendic, and R. Luft. 1978. Cellular localization of somatostatin. Metab. Clin. Exp. 27(Suppl 1): 1151-1159.

28. Goodman, R. H., P. K. Lund, J. W. Jacobs, and J. F. Habener. 1980. Pre-prosomatostatins: products of cellfree translations of messenger RNAs from anglerfish islets. J. Biol. Chem. 255: 6549-6552.

29. Shields, D. 1980. In vitro biosynthesis of somatostatin: evidence for two distinct prosomatostatin molecules. $J$. Biol. Chem. 255: 11625-11628.

30. Hobart, P., R. Crawford, L. Shen, R. Pictet, and W. J. Rutter. 1980. Cloning and sequence analysis of cDNAs encoding two distinct somatostatin precursors found in the endocrine pancreas of anglerfish. Nature (Lond.). 288: 137-141.

31. Joseph-Bravo, P., J. L. Charli, T. Sherman, H. Boyer, F. Bolivar, and J. F. McKelvy. 1980. Identification of a putative hypothalamic mRNA coding for somatostatin and of its product in cell free translation. Biochem. Biophys. Res. Commun. 94: 1004-1012.

32. Goodman, R. H., J. W. Jacobs, P. C. Dee, N. H. Bell, and J. F. Habener. 1981. Mammalian somatostatin: sequence of a cloned cDNA encoding a precursor. Proceedings 63rd Annual Meeting U. S. Endocrine Society. 93a. (Abstr.). 